\title{
Candomblé e políticas PÚBlicas de SAÚde em Salvador, Bahia
}

\author{
Ordep Serra ${ }^{1}$, Maria Cristina Santos \\ Pechine $^{2}$ e Serge Pechine ${ }^{3}$
}

\begin{abstract}
Resumo
No passado, as comunidades religiosas afro-brasileiras foram objeto da perseguição policial forte; além de racismo e intolerância religiosa, estaperseguição foi inspirada por um preconceito médico generalizado: a etnomedicina afro-brasileira foi categorizada como charlatanismo e os ritos entusiásticos dos terreiros como causa (ou sintoma) de desordens psíquicas. Os estudos antropológicos evidenciaram a inanidade deste preconceito e evidenciaram que os terreiros não são somente templos, mas também agências de serviço de saúde populares importantes. Em duas décadas passadas, o Movimento Negro Brasileiro teve êxito na proposição de uma nova política de saúde pública para os negros no Brasil; em particular, líderes dos terreiros no estado da Bahia continuaram criando novas formas de cooperação com organizações governamentais e não governamentais com este objetivo. Discutimos neste artigo o estado presente e os desenvolvimentos possíveis desta cooperação incipiente.
\end{abstract}

Palavras-chave: Candomblé. Saúde. Políticas Públicas. População negra. Intolerância religiosa.

\footnotetext{
${ }^{1}$ Docente do Departamento de Antropologia da FFCH/UFBA. Secretário Adjunto da Associação Brasileira de Antropologia. End. eletrônico: ordepserra@terra.com.br

${ }^{2}$ Mestranda em Antropologia pela Universidade Federal da Bahia. End. eletrônico: cristinapechine@ hotmail.com

${ }^{3}$ Doutorando em Sociologia, em co-tutela pela École des Hautes Études en Sciences Sociales EHESS Paris e pela Universidade Federal da Bahia. End. eletrônico: sergepechine@hotmail.com
} 


\title{
CANDOMBLÉ AND PUBLIC HEALTH POLICIES IN SALVADOR, BAHIA
}

\begin{abstract}
In the past, African-Brazilian religious communities were the object of strong police persecution, in addition to racism and religious intolerance, this persecution was inspired by a generalized medical prejudice: the African-Brazilian ethnomedicine was categorized as quackery and enthusiastic rites of yards as a cause (or symptom) of mental disorders. Anthropological studies revealed the senselessness of this bias and showed that the yards are not only temples but also important popular health service agencies. In the past two decades, the Brazilian Black Movement has succeeded in proposing a new public health policy for the black people in Brazil, in particular, leaders of the yeards in the state of Bahia continued creating new forms of cooperation with governmental and nongovernmental organizations with this goal. In this article we discuss the present state and possible developments in this incipient cooperation.
\end{abstract}

Keywords: Candomblé. Health. Public Policies. Black population. Religious intolerance.

este artigo, trataremos da relação entre os terreiros de candomblé de
Salvador, o poder público e as políticas de saúde nesta cidade, tendo em
vistas as novas propostas de colaboração entre os terreiros e órgãos de saúde do município e do estado. Tomamos como base uma pesquisa recentemente concluída. ${ }^{4}$ Vamos começar com uma pergunta ingênua: o que são mesmo terreiros de candomblé? Como eles são vistos, na Bahia, pelo poder público (e pela sociedade)?

A resposta mais simples logo acorre: terreiros são templos religiosos. Mas dá-se que, na prática, eles nem sempre são reconhecidos como tais pelos órgãos de governo. Mesmo aqueles que alcançaram grande fama e prestígio, chegando a ter sua importância reconhecida formalmente pelo Estado brasileiro através do tombamento, ainda têm dificuldades para ver respeitado seu direito à imunidade

\footnotetext{
${ }^{4}$ A pesquisa Candomblé, Saúde e Solidariedade em Salvador, financiada pelo CNPQ e realizada entre os anos de 2006 e 2008; dela participaram os signatários deste artigo, o primeiro dos quais é seu coordenador.
} 
fiscal, direito este assegurado em lei a todos os templos religiosos pelo Artigo 150 da Constituição Brasileira. É significativo o exemplo da famosa Casa Branca do Engenho Velho, o primeiro templo afro-brasileiro tombado no país como patrimônio histórico nacional; recentemente este Ilê Axé voltou a sofrer a cobrança do IPTU (Imposto Predial e Territorial Urbano), com ameaça de arresto e leilão de seu terreno - aliás, uma Área de Proteção Cultural e Paisagística do município5.

É só um exemplo, que se destaca pelo grau de impertinência. Mas nada tem de excepcional. Quase todos os terreiros baianos arcam com taxas de que outros cultos estão isentos. Está claro que assim o próprio poder público os discrimina: na prática nem sempre os considera templos religiosos. Essa atitude reflete preconceitos arraigados.

Os mesmos preconceitos explicam a espantosa demora na constatação de uma evidência irrecusável para quem lida com planejamento em Salvador e estuda a evolução urbana da cidade: o fato de que terreiros são um tipo de assentamento muito importante neste complexo urbano. Seu número avultado e suas características especiais deveriam, desde muito, chamar a atenção dos técnicos que lidam com a ocupação e o uso do solo, com a gestão do espaço da metrópole baiana; mas foi apenas na década de 1980 que um órgão de planejamento da Prefeitura Municipal de Salvador (PMS) os abordou assim (SALVADOR, 1982). Hoje, verifica-se uma nova preocupação em levá-los em conta na leitura da urbe. Um grande passo nessa direção foi o recente mapeamento dos terreiros empreendido pela PMS através de suas Secretarias da Habitação e da Reparação, em parceria com o Centro de Estudos Afro-Orientais da Universidade Federal da Bahia. No entanto, ainda não há estudos suficientes sobre a forma de manejo do espaço que esses assentamentos representam e uma política que assim os contemple ainda está em esboço ${ }^{6}$. Além disso, uma coisa é certa: demorou-se ainda mais a reconhecer os centros de culto das religiões de matriz africana como agências de saúde.

\footnotetext{
${ }^{5}$ A Prefeitura Municipal do Salvador só desistiu dessa esdrúxula medida depois de receber uma enxurrada de protestos de todo o Brasil e do exterior.

${ }^{6}$ Houve um avanço: a Secretaria da Reparação da PMS já promete empenhar-se na regularização da situação fundiária dos terreiros. Mas trata-se de definições recentes, que ainda estão por traduzirse em práticas administrativas concretas.
} 


\section{SAÚdE DA POPULAÇÃO NEGRA E POLÍTICAS PÚBLICAS}

De modo decisivo, os pesquisadores logo tomaram plena consciência de que os terreiros são importantes agências de saúde, núcleos de uma ação social que repercute sobre segmentos consideráveis da sociedade 7 . Mas esta compreensão não se impôs de imediato no plano prático das políticas públicas, nas esferas de governo - onde apenas começa a fazer-se valer.

Iniciativas da sociedade civil - de ONG's e de associações ligadas de algum modo ao candomblé - abriram caminho para um novo encontro entre os interesses dos terreiros e dos órgãos de governo encarregados do cuidado da saúde pública, em Salvador. A possibilidade de desenvolvimento sistemático de uma ação efetiva desses órgãos nos terreiros e com os terreiros abriu-se pouco depois, no horizonte de um processo novo, protagonizado pelo movimento negro: o processo que culminou com a proposição de uma política de saúde específica para a população negra.

Passos decisivos foram dados em 1996, com uma famosa Mesa Redonda sobre a Saúde da População Negra de que participaram cientistas, militantes de movimentos sociais e técnicos do Ministério da Saúde. Em 1997, este Ministério chegou a elaborar, com base nos resultados da dita Mesa Redonda, a proposta de uma Política de Saúde para a População Negra (OLIVEIRA, 2002, p. 243).

0 avanço maior se deu já no começo do novo século, refletindo o impacto da Terceira Conferência Mundial de Combate ao Racismo, Discriminação Racial, Xenofobia e Intolerância Correlata, realizada em Durban, na África do Sul, entre 31 de agosto e 8 de setembro de 2001, com expressiva participação de militantes brasileiros (MAGGIE; FRY, 2004; MAIO, 2008; SANTOS, 2005). Nesse mesmo ano, teve lugar no Rio de Janeiro uma reunião de que participaram membros de organismos internacionais (OPAS, UNICEF, UNESCO, PNUD), militantes do movimento negro e membros de instituições universitárias (UFBA, UFMT, UFF), além de representantes da Secretaria de Saúde do governo do estado fluminense; os trabalhos culminaram com a elaboração de um documento (OPAS, 2001) intitulado Política Nacional de Saúde da População Negra: uma questão de equidade. Deste documento já consta a demanda de reconhecimento oficial da medicina popular "de matriz africana".

\footnotetext{
${ }^{7}$ Ver, por exemplo: Loyola (1984); Montero (1985); Ratis e Silva (1987); Serra (1978); Verger (1995); Barros (1993); Serra Et Al. (2000); Serra et al. (2002).
} 
No ano de 2003, foi criada pela Presidência da República a Secretaria Especial de Promoção de Políticas de Igualdade Racial (SEPPIR); no ano seguinte, por ocasião do Primeiro Seminário Nacional de Saúde da População Negra, foi instituído um comitê técnico para a implementação de suas propostas, integrado por membros da SEPPIR e do Ministério da Saúde. Já em 2006, no contexto do Segundo Seminário sobre o tema, oficializou-se a Política Nacional de Saúde da População Negra; no mesmo ano, o Conselho Nacional de Saúde lançou o Programa de Combate ao Racismo Institucional na Saúde (MONTEIR0, 2008; MAIO, 2008).

Nessa altura, já existia uma ampla mobilização do povo-de-santo, um movimento expressivo de comunidades religiosas afro-brasileiras empenhadas em garantir direitos à saúde. Assim é que no ano de 2003 realizou-se em Salvador, na chamada Praça de Oxum do Terreiro da Casa Branca do Engenho Velho (de nome litúrgico Ilê Axé Iyá Nassô Okâ), a I Feira de Saúde do Terreiro da Casa Branca, promovida pela Associação São Jorge do Engenho Velho (que representa, no plano civil, o Egbé Iyá Nassô, ou seja, a comunidade do referido templo) e pelo Grupo Hermes de Cultura e Promoção Social, com apoio da Secretaria de Saúde da PMS, do Centro Ecumênico de Serviços - CESE e de Koinonia, Presença Ecumênica e Serviços ${ }^{8}$ o evento teve lugar no contexto do I Seminário de Saúde da População Negra, organizado, em 2003, pela Universidade Federal da Bahia, em articulação com outras instituições e com significativa participação do povo-de-santo. 0 sucesso da iniciativa - que viabilizou o encontro entre lideranças das religiões de matriz africana, pesquisadores e técnicos em saúde da Bahia e de outros estados - levou à realização do I Seminário Nacional de Saúde da População Negra, o qual teve lugar no ano seguinte, em Brasília, com a participação de gestores de diversos municípios de todo o país. A II Feira de Saúde da Casa Branca, realizada em novembro de 2004, na mesma Praça de Oxum, de novo mobilizou não só o Egbé Iyá Nassô e a população das vizinhanças como também o povo-de-santo de vários outros templos de culto aos orixás, além de muitas entidades representativas da população negra soteropolitana, de ONG's e de agremiações diversas, com apoio da PMS e patrocínio da ONG CESE?.

\footnotetext{
${ }^{8} 0$ Ilê Axé Iyá Nassô Oká foi o primeiro terreiro baiano a integrar-se ao movimento ecumênico, através de Koinonia, já em finais da década de 1980, quando a Associação São Jorge do Engenho Velho teve parte ativa na criação do Projeto Egbé.

${ }^{9}$ Feiras de Saúde têm sido realizadas desde então em diversos terreiros de Salvador. É no Terreiro da Casa Branca que nasceu esta iniciativa.
}

CANDOMblé e POLíticas PÚBlicAs...

O. Serra, M. C. S. Pechine e S. Pechine

- 167 
As discussões aí realizadas já desenhavam uma proposta política. Consolidava-se também um paradigma que logo seria adotado oficialmente: no ano de 2005, a Secretaria de Saúde da Prefeitura Municipal do Salvador assumiria o encargo da realização de feiras de saúde nos terreiros soteropolitanos, tornando essa iniciativa uma sua atividade sistemática.

Em março de 2003, durante o II Seminário Nacional Religiões AfroBrasileiras e Saúde, realizado em São Luís do Maranhão, foi criada a Rede Nacional de Religiões Afro-Brasileiras e Saúde, que associa adeptos de diferentes cultos de matriz africana (candomblé, umbanda, encantaria, batuque, xangô, xambá etc.), interagindo com gestores e profissionais da área de saúde, integrantes de ONG's e de órgãos de governo, pesquisadores e lideranças do movimento negro ${ }^{10}$. Atualmente, a Rede conta com vinte e três núcleos espalhados pelo Brasil e tem representações em doze estados, a Bahia inclusive (SILVA, 2007).

Ainda no começo deste século verificaram-se, no particular, mudanças significativas na Bahia, com o acolhimento, no plano governamental, de reivindicações importantes do movimento negro: já em 2003, deu-se a criação da Secretaria Municipal da Reparação - SEMUR da Prefeitura Municipal do Salvador; em fevereiro de 2005 foi constituído o Grupo de Trabalho de Saúde da População Negra (GTSPN/PMS), em que colaboram a SEMUR e a SMS (Secretaria Municipal da Saúde; cf. SALVADOR, 2006); esta última passou, então, a contar com uma Assessoria de Promoção da Equidade Racial em Saúde ASPERS. Ainda em 2005, a SMS promoveu um encontro de que participaram, além de membros de sua Coordenação de Saúde Ambiental e do GTSPN, lideranças de doze terreiros soteropolitanos, dirigentes de destacadas organizações do povo-desanto e representantes da Pastoral Afro da Igreja Católica. Iniciou-se oficialmente o diálogo.

Prosseguindo nessa busca de entendimento, nos dias 14 e 15 de setembro de 2007 as Secretarias de Saúde de Salvador e do município vizinho de Lauro de Freitas promoveram o seu I Seminário de Religiões Africanas e Saúde, com a participação de destacados representantes de comunidades do candomblé e equipes técnicas não só de órgãos dos referidos municípios como também do governo do Estado da Bahia, principalmente de sua Secretaria da Promoção da

\footnotetext{
${ }^{10}$ São seus objetivos lograr o reconhecimento dos saberes tradicionais dos sacerdotes dos terreiros e exigir das autoridades um atendimento de qualidade para o povo-de-santo e toda a população negra.
} 
Igualdade. Proclamou-se a necessidade de diálogo franco entre as lideranças do candomblé e os agentes de saúde dos órgãos governamentais; tratou-se de refletir sobre o impacto do racismo e da intolerância religiosa na saúde da população negra. Um plano de ação foi traçado.

As propostas resultantes do referido Seminário cobriram um amplo (talvez muito amplo) leque: desde "sistematizar a visita de turistas aos terreiros", garantindo a estes estabelecimentos "funcionamento/subsídios, sem discriminação" até "utilizar a estratégia da compostagem da matéria orgânica oriunda das oferendas das religiões de matriz africana". Mas o foco principal incidiu em um duplo objetivo: a capacitação dos profissionais de saúde "para trabalhar em parceria com os terreiros" e a concomitante "formação de agentes multiplicadores nos candomblés" a fim de "desenvolver ações de educação em saúde”. Até agora, pouco se conseguiu avançar para a efetivação desses bons propósitos.

$\mathrm{Na}$ Carta que resumiu as conclusões do encontro, deu-se grande ênfase à necessidade de sensibilização e formação tanto de lideranças do povo-desanto como de profissionais de saúde atuantes nos órgãos governamentais, com vistas a garantir-lhes, a uns e outros, a possibilidade de uma eficaz colaboração. Reclamou-se o apoio dos sistemas de saúde estadual e municipal à ensejada tarefa de organização de uma rede integrada distrital de terreiros de candomblé a ser acionada com vistas ao desenvolvimento de ações em saúde nos municípios de Lauro de Freitas e Salvador. Insistiu-se, ainda, na importância de "estimular a participação de representantes das religiões de matriz africana nos espaços de controle social [dos serviços de saúde]" (SALVADOR, 2008).

Como não podia deixar de ser, a problemática do racismo e da intolerância religiosa constituiu um foco destacado de discussão: mobilizou todo um grupo de trabalho que fez uma série de propostas objetivas, reclamando, por exemplo, a capacitação da ouvidoria da saúde (do estado e do município) para atender adequadamente às queixas e denúncias relativas a problemas dessa ordem e a "educação dos profissionais de saúde" com o mesmo fim. Chegou-se a sugerir uma "articulação com universidades e [outros] centros de formação com vistas a inserir [nos currículos dos cursos que formam os peritos nessa área] disciplinas como antropologia cultural e outras que abordem a temática racial e a da diversidade religiosa". 
A ASPERS/SMS assumiu como tarefa sua a realização dessas propostas no município de Salvador. Entre os obstáculos que enfrenta, merecem destaque a falta de recursos e as deficiências crônicas de um serviço municipal precário, mal equipado, carente de meios. Quando postos de saúde ficam sem água ou têm cortado o telefone por falta de pagamento, quando as equipes técnicas carecem de apoio logístico e de material indispensável para seu trabalho, quando os funcionários são mal remunerados, permanecem pouco equipados e se sentem desestimulados, não é fácil implantar programas novos. Manter a rotina já representa um desafio. As coisas ficam ainda mais difíceis quando se verifica, no corpo técnico, uma certa acomodação às limitações rotineiras.

0 desiderato da nova política que se tenta pôr em prática é duplo, como facilmente se infere do que já foi exposto: por um lado, busca-se contemplar efetivamente o povo-de-santo nas ações de saúde pública, prestando-lhe o devido atendimento, sem discriminação; por outro lado, persegue-se o objetivo de uma aliança entre órgãos de governo e as comunidades de candomblé, com vistas à melhoria do cuidado da saúde da população negra (e do povo em geral).

Quanto a este segundo ponto, o ideal é que os terreiros, com seu prestígio e capilaridade, possam vir a constituir-se em centros de atenção onde, sem prejuízo do exercício de suas práticas tradicionais (religiosas e terapêuticas), também se apóie o serviço público de saúde: onde, por exemplo, como já ocorre em templos de outras religiões, exerça-se vigilância sobre a mortalidade materna e infantil, reúnam-se para mútua ajuda e recebimento de orientação mulheres grávidas e lactentes, idosos, grupos solidários empenhados em compartir o cuidado do diabetes, da hipertensão, da anemia falciforme e de outros síndromes de significativa incidência nessa faixa da população (carente, negra na maioria); onde membros da comunidade do terreiro e de seu entorno tenham acesso a orientações sobre DST's e AIDS e se proceda à distribuição de preservativos; onde, mediante o treinamento de agentes comunitários recrutados nesse meio e capacitados por quem de direito - com uma preparação especial para tratar da problemática específica da saúde da população negra, possam se efetuar, quando necessário, os devidos encaminhamentos para serviços médicos do SUS (Sistema Único de Saúde) ${ }^{11}$. Chegar a isso demanda, é claro, tempo e recursos. Estes são escassos, às vezes somente "virtuais". Pois as verbas destinadas nem sempre chegam a tornar-se disponíveis.

${ }^{11}$ Ver Oliveira (2002, p. 63). 


\section{INTOLERÂNCIA RELIGIOSA, VIOLÊNCIA E SAÚDE}

Mas não é só a falta de meios (financeiros e de infra-estrutura) que se põe como obstáculo para a consecução de objetivos que os órgãos de governo em tese consagraram. Há outros óbices muito graves a ser vencidos. Um deles tornou-se a causa principal da preocupação manifesta em todos os diálogos entre o povo-desanto e as autoridades responsáveis pela saúde pública em Salvador: a intolerância religiosa.

No encontro há pouco evocado, este problema foi claramente colocado: os agentes comunitários de saúde e de zoonoses se negam a realizar ações de saúde nos terreiros. Em suma, quando se trata de atender aos candomblés, eles esquivam o desempenho de ações rotineiras que são de sua incumbência normal. 0 problema foi apontado de forma recorrente pelos entrevistados no curso da pesquisa CASOS em que se baseia este trabalho; foi e continua sendo assunto principal de discussões nos encontros e oficinas realizadas pela ASPERS nos distritos sanitários de Salvador, como acusa, por exemplo, o Relatório da Primeira Oficina de Religião de Matriz Africana e Saúde, que reuniu os distritos de Brotas, Boca do Rio, Cabula, Barra e Rio Vermelho; foi consenso então que "os primeiros intolerantes são os agentes comunitários". Reiterou-se isso com muita ênfase na II Oficina, também realizada em maio de 2008, reunindo os distritos de Centro Histórico, Itapuã e Pau da Lima. Isto significa que o povo-de-santo é diretamente marginalizado na provisão da saúde pública, em Salvador. E esta discriminação dificilmente resulta coibida.

Os membros do citado Seminário de Salvador/Lauro de Freitas tiveram razão de sobra para cobrar um trabalho de educação continuada voltado para a superação do preconceito entre esses funcionários públicos; exerceram seu direito ao exigir a realização de inquérito administrativo em casos de tal ordem; com justiça reclamaram a criação de sanções efetivas que combatam semelhante atitude e pediram melhor divulgação do papel da Ouvidoria nos órgãos onde isso se verifica. Mas trata-se de um ideal ainda distante da realização, como nossa pesquisa evidenciou. É imperioso concluir que o Programa de Combate ao Racismo Institucional ainda não funciona como deveria. Ora, se mesmo o trabalho rotineiro dos agentes de saúde do aparelho de estado acontece de ser sonegado ao povo-desanto, por aí já se vê a dificuldade de passar à colaboração, todavia indispensável, entre os órgãos em que eles atuam e os candomblés de Salvador. 
A discriminação tem por base primeira um preconceito sedimentado: a convicção a priori de que o povo-de-santo é ignorante, supersticioso, portador de idéias "atrasadas", dado a práticas irracionais, incompatíveis com o ideal de saúde. Combinam-se para alimentar essa convicção o racismo difuso que, mais ou menos veladamente, perpassa a sociedade brasileira (nutrido por deficiências da educação básica e pelos reflexos ideológicos de uma desigualdade crônica) e, por outro lado, a formação profissional precária de muitos agentes de saúde. Essa má formação inculca em muitos o sentimento de que práticas inspiradas no ideário de uma camada "inferior" vêm a ser, por força, inconciliáveis com a verdade médica, incompatíveis com uma verdadeira cultura da saúde. Mas não é tudo. Além disso, há o preconceito cultivado, estimulado, construído de forma doutrinária, alimentado por intolerância religiosa ensinada, pregada sistematicamente.

A "guerra santa" movida por igrejas neo-pentecostais de missão contra as religiões de matriz africana tem tido uma propagação extraordinária em todo 0 Brasil e é cada vez mais acirrada na Bahia. ${ }^{12}$ Os agentes de saúde do aparelho de estado que aderiram às novas igrejas fundamentalistas sentem verdadeira repulsa pelos candomblés, que consideram "casas do diabo". Ódio e temor juntam-se em sua atitude para com o povo-de-santo e os levam a excluí-lo de seu cuidado, do horizonte de sua prática profissional.

É considerável o impacto da nova investida contra os ritos afro-brasileiros, promovida com virulência e com recursos muito poderosos por empresas eclesiais que têm o controle de meios de comunicação de massa e sabem muito bem empregá-los. Seus pastores promovem a incriminação do candomblé, da capoeira, das tradições negras - e logram sucesso inegável em induzir a autorejeição de homens e mulheres pobres, humilhados por preconceitos incidentes sobre sua condição de cor, de classe, de origem; fazem-no com uma pregação enfática baseada no convite a abandonar, em troca de sucesso, uma identidade sentida como deteriorada. Desse modo, levam muitos a se dessolidarizar dos mais

\footnotetext{
${ }^{12} 0$ Terreiro da Casa Branca do Engenho Velho já foi apedrejado por fanáticos de uma igreja pentecostal durante a celebração de uma festa. Outros terreiros de Salvador foram invadidos por "exorcistas" da mesma extração. A Ialorixá Mãe Gilda do Terreiro Ilê Axé Abassá de Ogum sofreu também agressões de fanáticos e veio a falecer em 21 de janeiro de 2001. Sua filha deu curso a uma ação por danos morais. Recentemente, a condenação da IURD neste caso foi confirmada pelo Superior Tribunal de Justiça. 0 dia 21 de janeiro tornou-se Dia de Combate à Intolerância Religiosa para os adeptos do candomblé.
} 
próximos - e principalmente dos mais envolvidos com os códigos da negritude assim rejeitada.

0 povo-de-santo é duplamente atingido nesse processo. A intolerância religiosa afeta os fiéis do candomblé ao infligir-lhes vexames (agressões e calúnias) que geralmente ficam impunes; por outro lado, produz um cerceamento de seus direitos, quando leva profissionais a marginalizá-los e mesmo a excluí-los da prestação de serviços públicos a que fazem jus.

Os interessados em estabelecer uma nova aproximação entre os órgãos incumbidos do cuidado da saúde pública e o pessoal dos terreiros têm sempre de começar o diálogo abordando este difícil tema, que desperta os mais vivos debates e é um prelúdio inevitável a qualquer proposição de trabalho conjunto. Hoje em dia, quando se vai tratar de saúde como o povo-de-santo, essa questão logo aflora.

Uma constatação se impõe: a intolerância religiosa que se espalha na Bahia é causa de privação e sofrimento para um segmento importante da população do Estado, em particular de sua capital: o povo-de-santo, os sacerdotes e os adeptos do culto dos orixás. Produz, assim, efeitos negativos sérios: por um lado, embaraça o desempenho de um sistema tradicional de ação para a saúde que efetivamente socorre as aflições de muitos; por outro, impede uma ação mais efetiva do poder público nesse campo, na medida em que tolhe uma colaboração de cuja importância não é possível duvidar.

Soma-se este agravo a outros fatores que hoje conformam um quadro de grandes dificuldades para o povo do candomblé. Dá-se que a maioria absoluta dos terreiros baianos se localiza em áreas pobres da metrópole, em zonas desprovidas de infra-estrutura satisfatória, saturadas pelo crescimento desordenado, mal servidas de equipamentos e serviços públicos fundamentais; em muitos desses espaços, a degradação ambiental, hoje galopante na capital da Bahia, atinge níveis críticos. $\mathrm{E}$ a insegurança prevalece. A criminalidade, que tem tido crescimento exponencial na Região Metropolitana de Salvador nos últimos anos ${ }^{13}$, revela-se quase infrene em muitos de seus bairros de maioria negra e pobre, sujeitos à violência já rotineira das gangs de narcotraficantes que os "zoneiam” e se dão feroz combate, colocando em risco toda a população, acossada também pelas investidas arbitrárias de uma polícia em grande medida despreparada, brutal, corrupta e contaminada pelo

\footnotetext{
${ }^{13} 0$ documento "Enfrentamento da Violência em Salvador", emanado da assembléia de 31 de julho de 2008 do Fórum Comunitário de Combate à Violência, mostra com clareza a dimensão crítica do problema.
}

CANDOMblé e POLÍticAS PÚBlicAs...

O. Serra, M. C. S. Pechine e S. Pechine

- 173 
banditismo. São áreas em que o desemprego e o subemprego atingem picos e os indicadores epidemiológicos se mostram os mais negativos. Na Salvador informal, tremendamente empobrecida e desfigurada, a violência epidêmica dizima jovens de maneira constante - e a maioria dessas vítimas é de negros entre quatorze e vinte e cinco anos.

Numa reunião de que participamos recentemente com expressivas lideranças do povo-de-santo, entre os temas discutidos como os mais preocupantes para o candomblé, tiveram destaque: (1) a intolerância religiosa; (2) o crescimento da violência em Salvador; (3) a perda de espaço (e em particular de área verde) pelos terreiros. Esses tópicos já se tornaram recorrentes, quase obsessivos, nas entrevistas com gente do candomblé realizadas na pesquisa que desenvolvemos. Está claro que eles se interligam e se relacionam todos com a problemática da saúde da população negra.

Estudos realizados no final do século passado já mostravam com clareza as graves dificuldades enfrentadas pelos sacerdotes dos ilê axé ${ }^{14} \mathrm{com}$ a progressiva desaparição de trechos de mato que seus terreiros incorporavam ou que se achavam em sua vizinhança, tornando muito árdua a coleta de vegetais necessários para a realização de vários ritos e para a preparação de fármacos tradicionais da sua terapêutica (SERRA, 1999); tal carência acarreta a ameaça de uma certa erosão do conhecimento etnobotânico dessas comunidades. Ainda se pode verificar que em muitos bairros soteropolitanos as manchas verdes são um indicativo da existência de terreiros; mas elas progressivamente diminuem e as Casas de Santo se vêem, com freqüência, mutiladas por uma ocupação desordenada dos espaços nessas áreas saturadas; são vítimas da ganância predominante no mercado imobiliário de Salvador, da iniquidade da distribuição das terras na capital baiana. No código do candomblé, essas perdas também representam perda de saúde, de bem estar.

0 povo-de-santo tem uma clara percepção de que a violência crescente é uma doença terrível do coletivo; comparte os riscos e danos de sua infrene propagação. As redes de solidariedade que se entretecem nos terreiros são um fator de coesão muito poderoso. Como se sabe, o tecido social se esgarça quando organizações populares desse tipo são ameaçadas. Elas são um obstáculo ao domínio da violência. Uma prova dolorosa disso já foi dada no Rio de Janeiro, onde bandos de criminosos têm-se empenhado em expulsar candomblés dos

${ }^{14}$ Casa de axé ou terreiro. 
territórios que dominam, na Baixada Fluminense ${ }^{15}$. Na Bahia, corre-se perigo real com a "guerra santa" hoje movida ao culto dos orixás. A intolerância religiosa já se tornou um grave problema de saúde pública nesta terra.

A abertura do diálogo e a busca da colaboração (ainda incipiente) entre os candomblés baianos e os órgãos de saúde pública atuantes em Salvador se devem à iniciativa de organizações da sociedade civil: a lideranças dos terreiros, a ong's ligadas aos egbe $e^{16}$ e aos movimentos negros. Militantes que assumiram cargos na estrutura do governo municipal deram impulso a essa tentativa. Mas ela não avançou muito, travada pela falta de recursos e pelas limitações de poder que esses novos agentes de mudança sofrem no seu trabalho; a adesão dos principais gestores à proposta de uma política de saúde para a população negra é muito mais retórica do que efetiva. E o quadro de desorganização interna do serviço de saúde municipal é de fato muito grave em Salvador. Há também a barreira das resistências internas que se verificam nos quadros técnicos.

Até o momento, a iniciativa mais exitosa em termos de aproximação entre o candomblé e o serviço de saúde do município é a promoção das feiras de saúde nos terreiros, de acordo com um modelo que a PMS adotou, mas foi criado nos próprios egbé. Essas feiras têm características próprias, que as singularizam. Têm muita coisa em comum, é claro, com as que são realizadas em diferentes espaços comunitários; mas têm algo mais, além da prestação de serviços e informações ao público (vacinação de pessoas e animais domésticos, pequenas conferências com esclarecimentos sobre problemas de saúde de diversas ordens, distribuição de preservativos, controle de hipertensão, pesagem de crianças, breves consultas, orientação didática odontológica etc.) Todavia, como logo percebemos em nossa pesquisa, nenhuma feira de saúde que se limitar a essas atividades terá êxito em um terreiro de candomblé baiano.

Evidência disso já existe. Há cerca de duas décadas, ensaiou-se fazer uma "feira-padrão" no Terreiro da Casa Branca - e o resultado foi sofrível. Tempos depois, com o protagonismo do próprio pessoal dos terreiros, a feira de saúde que se realizou nesse mesmo candomblé teve um sucesso inegável, produzindo o modelo que se difundiu pelas Casas de Santo baianas.

\footnotetext{
${ }^{15}$ Jornal Extra, 15 de março de 2008. Fala Egbé (Informativo do Projeto Egbé/Koinonia) agosto de 2008.

${ }^{16}$ Comunidade do terreiro de candomblé.
} 
No evento assim reestruturado, há sempre espaço para cantos e danças; há barracas onde se vende, além de artesanato relacionado com "coisas de santo", comida e bebida. Não raro, sucedem nessas feiras exibições de grupos de teatro juvenil e de capoeira; cantores populares às vezes comparecem. Freqüentemente, tudo acaba em samba de roda. As crianças da redondeza são mobilizadas através de gincanas e participam com grande entusiasmo. Há também mesas redondas nas que se discutem assuntos diversos, de interesse do pessoal dos terreiros. Mas seja qual for o temário escolhido, um assunto sempre retorna: a intolerância religiosa.

Na IV Feira de Saúde do Terreiro da Casa Branca, que teve lugar em setembro de 2008 na Praça de 0xum do Engenho Velho, o temário escolhido por lideranças da Casa anunciava: "A saúde da população negra de Salvador, a violência urbana e políticas públicas para os terreiros de Candomblé". Mas a intolerância religiosa também foi abordada e discutida. E deu-se uma novidade: estando próximas as eleições para prefeito da cidade, os "prefeituráveis" foram convidados a participar (apenas dois compareceram). A iniciativa desse convite foi também de lideranças do terreiro.

A singularidade das feiras de saúde realizadas nos egbé tem a ver com o ideário do povo-de-santo. 0 nome "feira" sugere movimentação, diálogo e comércio; "saúde", no entendimento desses grupos de culto, por força implica alegre expansão. Uma feira de saúde em que não se coma bem, em que falte bebida e animação, sem risos, danças e brincadeiras, seria fraca, desanimada. Para ser feira, também precisa incluir algum movimento de compras e vendas, mesmo em pequena escala. Em suma, dá-se que, para os devotos dos orixás, a vida saudável se manifesta como alegria, exige dança e canto. Só assim pode a saúde ser promovida.

Os orixás também devem ser homenageados nesses contextos: segundo 0 povo-de-santo, são eles que garantem o bem estar de todos. Geralmente, cada feira tem um patrono divino. Ainda que não aconteçam atos litúrgicos como os que os terreiros celebram no curso de sua atividade religiosa comum, sempre alguma cantiga-de-santo deve ser entoada, alguma oração feita, pois se tem consciência de estar em território sagrado. Esquecer os orixás não seria saudável. Por outro lado, o novo interesse pelas mesas redondas e debates mostra uma crescente politização do povo-de-santo, ou melhor, de um segmento deste cada vez mais empenhado em discutir sua situação e os problemas da cidade. Isso, sem dúvida, é um bom sinal para a saúde dos baianos. 


\section{CONSIDERAÇõES FINAIS}

Todavia, se esta iniciativa de promoção sistemática de feiras de saúde em terreiros de candomblé baianos tem tido êxito, se os seminários, encontros e debates sobre o assunto "saúde da população negra" têm prosperado e gerado novas propostas, o fato é que o quadro de saúde dessa população ainda não mudou; os terreiros continuam sofrendo discriminação e a nova política de colaboração entre os órgãos de saúde pública e o candomblé continua valendo quase somente no papel e na voz entusiasmada de seus defensores. Mas, a esperança cresce. E não há dúvida de que já se deu um grande avanç̧, agora que o povo-de-santo se faz ouvir no cenário das discussões sobre saúde pública em Salvador.

\section{REFERÊNCIAS}

BARROS, José Flávio Pessoa de. 0 segredo das folhas. Sistema de classificação de vegetais no candomblé jeje-nagô. Rio de Janeiro: Editora Pallas, 1993.

LOYOLA, Maria Andréia. Médicos e curandeiros: conflito social e saúde. São Paulo: Difel, 1984.

MAGGIE, Yvonne e FRY, Peter. A reserva de vagas para negros nas universidades brasileiras. Estudos Avançados, São Paulo, v. 18, (50), 2004, p.67-80.

MAIO, Marcos Chor. Qual retrato do Brasil? Raça, biologia, identidades e política na era da genômica. In: PINHO, Osmundo \& SANSONE, Lívio. Raça: novas perspectivas antropólogicas. Salvador: EdUFBA, 2008.

MONTEIRO, Simone; MAIO, Marcos Chor. Cor/raça, saúde e política (1995-2006). In: PINHO, Osmundo \& SANSONE, Lívio. Raça: novas perspectivas antropólogicas. Salvador: EdUFBA, 2008.

MONTERO, Paula. Da doença à desordem: a cura mágica na Umbanda. Rio de Janeiro: Graal, 1985.

OLIVEIRA, Fátima. Saúde da população negra. Brasília: Organização PanAmericana da Saúde, 2002.

OPAS. Política nacional de saúde da população negra: uma questão de equiidade. Documento do Workshop Interagencial de Saúde da População Negra, 6-7 dez. 2001. Brasília:PNUD/OPAS/DFID/UNFPA/UNICEF/UNESCO/UNDCP/ UNAIDS/UNIFEM. 
PNUD. Atlas de Desenvolvimento Humano da Região Metropolitana de Salvador. In: <http://www.pnud.org.br/publicacoes/atlas_salvador/release_ IDHM_geografico.pdf $>$. Acessado em 13 de agosto de 2008.

RATIS e SILVA, Pedro. Exu/Obaluaiê e o arquétipo do médico ferido na transferência. In: MOURA, Carlos Eugênio Marcondes de. (org.). Candomblé: demarcando identidades. São Paulo: E.M. W. Editores, 1987.

SALVADOR. Órgão Central de Planejamento. Monumentos negros da Babia. Salvador, 1982.

SALVADOR. SECRETARIA MUNICIPAL DA SAÚDE. Diagnóstico de Saúde da População Negra de Salvador. Grupo de Trabalho de Saúde da População Negra, Salvador, 2006.

SANTOS, Jocélio T. dos. O poder da cultura e a cultura do poder. Salvador: Edufba, 2005.

SERRA, Ordep. Saúde e salvação na trilha das crianças: os erês num terreiro angola. Dissertação de Mestrado apresentada ao Programa de Pós-Graduação em Antropologia Social da Universidade de Brasília. Brasília, 1978.

. A etnobotânica do candomblé nagô da Bahia. In: CAROSO, Carlos; BACELAR, Jeferson (orgs.). Faces da tradição afro-brasileira. Rio de Janeiro: Pallas, 1999.

SERRA, Ordep et al. Farmácia e Cosmologia: A Etnobotânica do Candomblé na Bahia. Etnoecológica, México-DF, v. 4(6), 2000, p.11-32.

SERRA, Ordep; VELOZO, Eudes; BANDEIRA, Fábio; PACHECO, Leonardo (orgs.). O mundo das Folhas. Salvador: Universidade Estadual de Feira de Santana/ EdUFBA, 2002.

SILVA, José Marmo da. Religiões e saúde: a experiência da Rede Nacional de Religiões Afro-Brasileiras e Saúde. Saúde e Sociedade, São Paulo, v.16, n.2, 2007, p.171-177.

VERGER, Pierre. Ewé. O uso das folhas na sociedade yorubá. São Paulo: Companhia das Letras, 1995. 